\title{
Knowledge, attitudes and practices on tsetse and sleeping sickness among communities living in and around Serengeti National Park, Tanzania
}

\author{
S.M. KINUNG 'HI ${ }^{1 *}$, I.I. MALELE ${ }^{2}$, S.N. KIBONA ${ }^{3}$, L.E. MATEMBA ${ }^{3}$, J.K. SAHANI ${ }^{3}$, C. KISHAMAWE ${ }^{1}$ and \\ T.D.K. MLENGEYA ${ }^{4}$ \\ ${ }^{1}$ National Institute for Medical Research, Mwanza Centre, P.O. Box 1462, Mwanza, Tanzania \\ ${ }^{2}$ Tsetse and Trypanosomiasis Research Institute, P. O. Box 1026 Tanga, Tanzania \\ ${ }^{3}$ National Institute for Medical Research, Tabora Centre, P. O. Box 482, Tabora, Tanzania \\ ${ }^{4}$ Tanzania National Parks, P. O. Box 3134, Arusha, Tanzania
}

\begin{abstract}
A study was undertaken to investigate knowledge, attitudes and practices about sleeping sickness (human African trypanosomiasis) among communities living in and around Serengeti National Park (SENAPA). Structured questionnaires were administered to a total of 1490 consenting participants. Of the respondents, 924 (62\%) knew sleeping sickness, and 807 (87.3\%) knew the right place to seek healthcare. Of 924 who knew sleeping sickness, 386 (42\%) said the disease was present in the areas they live. Most respondents $(85.4 \%)$ knew that sleeping sickness infections were acquired in the bush and forest. The most common (69.3\%) sources of information about sleeping sickness were relatives and friends. Symptoms of sleeping sickness mentioned included abnormal sleep (45.2\%), fever (35.3\%), body malaise (14.5\%), headache (7.6\%) and lymph node enlargement (6.1\%). Of 1490 people interviewed $90.4 \%$ knew tsetse flies and $89.8 \%$ had been bitten by tsetse flies. The majority $(86.6 \%)$ of the respondents knew that sleeping sickness is transmitted through a tsetse bite. Activities that exposed people to tsetse bites included working in tsetse infested bushes/forests, grazing livestock in tsetse infested areas and hunting game animals. In conclusion, communities living in and around SENAPA were knowledgeable about tsetse and sleeping sickness. The communities can thus understand and support community based tsetse and sleeping sickness control programmes to ensure success.
\end{abstract}

Key words: Trypanosomiasis, knowledge, attitudes, practices, Tanzania

\section{Introduction}

Sleeping sickness (African human trypanosomiasis) is a severe and often fatal disease caused by protozoan parasites, namely Trypanosoma brucei rhodesiense in East and Southern Africa and T. brucei gambiense in West and Central Africa (WHO, 2002). Transmission of the disease is through a bite by tsetse flies of the genus Glossina. T. brucei rhodesiense infection is zoonotic affecting humans, livestock, game animals and most mammalian species. Sleeping sickness is found only in Sub-Saharan Africa within the limits of the geographical distribution of tsetse flies. There are around 200 endemic foci in 36 countries with an estimated 60 million people at risk and 300,000 new cases each year (WHO, 1998).

The Serengeti ecosystem has been known to be endemic for sleeping sickness since colonial times. Initial outbreak occurred in Ikoma in the northwestern part of Serengeti National Parkin 1922 and Maswa in the southern part in 1919-1921 (Davey, 1924; Hide, 1999). The outbreaks were associated with abundant game animals in the areas and Glossina swynnertoni was incriminated as the main vector (Swynnerton, 1923, 1925). The then Tanganyika government instituted rigorous control measures including clearing of vegetation, regrouping of isolated villages in reclaimed land, isolation and treatment of patients to prevent spread of infection, health education, destruction of wild animals, and closure of goldmines in Ikoma-Serengeti area. These measures led to a significant decrease in the incidence of the disease in the mid 1950s and early 1960s (Onyango \& Woo, 1971). However, the disease did not disappear completely as there was resurgence in 1964 (2 cases), 1965 (1 case), 1966 (4 cases), 1967 (6 cases), 1968 (14 cases) and 1969 (6 cases) (Moloo et al., 1971). This was followed by three decades during which no case was reported. However, in 2000/2001, 14 cases involving tourists, two cases involving local farmers and four cases involving local staff were reported. Among these, four deaths were confirmed (Mlengeya et al., 2002). These events show that the Serengeti ecosystem is still an active focus though the disease incidence fluctuates from time to time. This should be of great concern to the government as the area is being developed as a major tourist destination.

Recommended control measures for sleeping sickness include continuous surveillance of the population at risk, treatment of infected people and suppression of vector density using insecticide impregnated targets (WHO, 2002). Along with this, an equally important aspect in tsetse and sleeping sickness control is participation of the communities at risk. At the moment community participation is minimal in most endemic areas, which in turn have

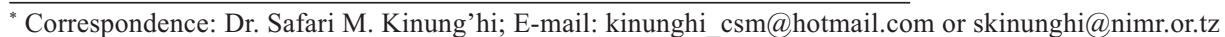


been attributed to community knowledge gaps about the disease and the vectors (Mboera et al., 2005). Limited community knowledge about any disease not only has a negative impact on success of prevention and control measures but also on health seeking behaviour.

The present study was therefore carried out to investigate community awareness, attitudes and practices about sleeping sickness transmission, symptoms, treatment and control measures with an ultimate goal of contributing to awareness of the affected communities, improvement of current control strategies and recommending sustainable community based control measures.

\section{Materials and Methods}

\section{Study area and population}

The study was conducted in Serengeti National Park (SENAPA) and selected adjacent villages in Bunda, Serengeti and Meatu districts in north-western Tanzania. In Bunda the villages included Kunzugu, Kihumbu, Mariwanda and Kyandege. In Serengeti the villages included Bwitengi, Nyichoka, Makundusi, Iharara, Singisi and Robanda. In Meatu the villages were Makao, Mbushi, Sapa, Mwanzagamba and Mbugayabang'hya. In SENAPA three sites were selected namely Seronera, Fort Ikoma and Naabi Gate. Agro-pastoral communities are found around the park, while communities living in the park are mainly park staff and their families. Occasional visitors to the park areas include tourists, tour guides, researchers, hunters and poachers.

\section{Study design}

The study was a cross sectional questionnaire survey. Overall 1490 people were interviewed in the course of implementation and they were from Bunda (280), Serengeti (364), Meatu (430) and SENAPA (416). Preliminary sensitization and mobilization meetings were held between researchers and the local communities during which the former explained to participants the objectives, procedures, benefits and discomforts of the study and sought consent of all eligible participants. During the study, all consenting participants attended willingly to pre-selected centres and were registered and interviewed. Only individuals 15 years and above were recruited into the study.

Structured questionnaires focusing on tsetse and sleeping sickness situation in the study area and on the participant's awareness, attitudes and practices about sleeping sickness symptoms, transmission, diagnosis and management were administered to all participants. The questionnaires also focused on past and current measures to prevent and control tsetse flies and sleeping sickness. The questionnaires also examined availability of diagnostic and healthcare services for sleeping sickness in the respective study areas.

\section{Data analysis}

After checking for quality and completeness, all data collected were entered into DbaseIV software using double entry system and analyzed using STATA version 8 (Stata Corp., College Station, TX, USA, 2003).

\section{Results}

Of the 1490 respondents, 924 (62\%) knew sleeping sickness and $800(86.6 \%)$ knew that the disease is transmitted through a tsetse bite. A total of 789 people $(85.4 \%)$ mentioned bushes and forests as sources where one can get sleeping sickness. In addition, 217 people $(23.5 \%)$ mentioned grazing areas as sources of infection. The most important reported sources of information about sleeping sickness were relatives and friends $(69.3 \%)$. Print materials including books and newspapers were mentioned as sources of information by $36 \%$ of the respondents.

The knowledge of the respondents on the symptoms and signs of sleeping sickness was poor, particularly for those living outside the National Park. The overall frequently mentioned symptoms included abnormal sleep ( $45.2 \%$ ), fever $(35.3 \%$ ), body malaise $(14.5 \%)$ and headache (7.6\%). Enlargement of lymphnodes was mentioned by only $6.1 \%$ of all respondents. The responses, however, varied between study areas (Table 1).

Table 1: Reported signs and symptoms of sleeping sickness as indicated by number (per cent) of respondents

\begin{tabular}{lcccc}
\hline Symptoms/signs & $\begin{array}{l}\text { Bunda } \\
\text { (n= 166) }\end{array}$ & $\begin{array}{l}\text { Serengeti } \\
(\mathbf{n = 1 8 8})\end{array}$ & $\begin{array}{l}\text { Meatu } \\
\text { (n= 196) }\end{array}$ & $\begin{array}{c}\text { SENAPA } \\
(\mathbf{n}=\mathbf{3 7 4})\end{array}$ \\
\hline Abnormal sleep & $32(19.3 \%)$ & $67(35.6 \%)$ & $57(29 \%)$ & $262(70 \%)$ \\
Fever & $62(22.2 \%)$ & $85(23.6 \%)$ & $49(11.4 \%)$ & $130(31.3 \%)$ \\
$\begin{array}{l}\text { Body malaise } \\
\text { Headache }\end{array}$ & $29(17.5 \%)$ & $26(13.8 \%)$ & $12(6 \%)$ & $67(17.9 \%)$ \\
Lymph node & $27(16.3 \%)$ & $15(8 \%)$ & $6(3 \%)$ & $22(5.9 \%)$ \\
enlargement & $12(7.2 \%)$ & $18(9.6 \%)$ & $12(6 \%)$ & $14(3.7 \%)$ \\
Abnormal appetite & $11(6.6 \%)$ & $6(3.2 \%)$ & $6(3 \%)$ & $15(4 \%)$ \\
$\quad$ Others & $13(7.8)$ & $7(3.7 \%)$ & $10(5 \%)$ & $6(1.6 \%)$ \\
\hline
\end{tabular}


A significant proportion (42\%) of the respondents was of the opinion that sleeping sickness was a public health problem. The majority of them $(87.3 \%) \mathrm{knew}$ the right place to seek medical care. However, $88.2 \%$ of the respondents said that diagnostic and treatment services were not available (Table 2). bushes and forests (85.4\%). A few respondents reported having been bitten by tsetse flies while in grazing areas $(23.5 \%)$ and even at home or office $(12.6 \%)$. Despite the knowledge that tsetse bites can be associated with disease even death, most of the respondents $(93.7 \%)$ took no action when bitten by

Table 2: Community knowledge on the availability of healthcare services for sleeping sickness in the survey areas

\begin{tabular}{lllll}
\hline Variable & $\begin{array}{l}\text { Bunda } \\
(\mathrm{n}=162)\end{array}$ & $\begin{array}{l}\text { Serengeti } \\
(\mathrm{n}=172)\end{array}$ & $\begin{array}{l}\text { Meatu } \\
(\mathrm{n}=156)\end{array}$ & $\begin{array}{l}\text { SENAPA } \\
(\mathrm{n}=370)\end{array}$ \\
\hline $\begin{array}{l}\text { Treatment } \\
\text { Hospital medicines }\end{array}$ & & & \\
$\quad$ Traditional medicines & $132(81.5 \%)$ & $158(91.9 \%)$ & $134(85.9 \%)$ & $363(98.1 \%)$ \\
Others & $6(3.7 \%)$ & $3(1.7 \%)$ & $12(7.7 \%)$ & $1(0.3 \%)$ \\
Do nothing & $5(3.1 \%)$ & $1(0.6 \%)$ & $2(1.3 \%)$ & $2(0.5 \%)$ \\
Don t know & $18(11.2 \%)$ & $8(4.7 \%)$ & $8(5.1 \%)$ & $1(0.3 \%)$ \\
& $1(0.6 \%)$ & $2(1.2 \%)$ & 0 & $3(0.8 \%)$ \\
Place to seek healthcare & & & & $367(98.1 \%)$ \\
Health facility & $139(86.9 \%)$ & $157(84.4 \%)$ & $143(73.7 \%)$ & 0 \\
Traditional healer & $4(2.5 \%)$ & $2(1 \%)$ & $10(5.2 \%)$ & $02(0.5 \%)$ \\
Others & $5(3.1 \%)$ & $6(3.2 \%)$ & $1(0.5 \%)$ & $5(1.3 \%)$ \\
Don t know & $12(7.5 \%)$ & $21(11.3 \%)$ & $40(20.6)$ & $63(16.8 \%)$ \\
Availability of treatment & $12(7.4 \%)$ & $18(9.6 \%)$ & $8(4.1 \%)$ & $305(81.5 \%)$ \\
Yes & $147(90.2 \%)$ & $169(89.9 \%)$ & $187(95.9 \%)$ & $6(1.6 \%)$ \\
No & $4(2.5 \%)$ & $1(0.5 \%)$ & 0 & \\
Don t know & & & & \\
\hline
\end{tabular}

Table 3: Community awareness of the risks associated with a tsetse bite

\begin{tabular}{lllll}
\hline Variable & $\begin{array}{l}\text { Bunda } \\
(\mathrm{n}=277)\end{array}$ & $\begin{array}{l}\text { Serengeti } \\
(\mathrm{n}=351)\end{array}$ & $\begin{array}{l}\text { Meatu } \\
(\mathrm{n}=427)\end{array}$ & $\begin{array}{l}\text { SENAPA } \\
(\mathrm{n}=408)\end{array}$ \\
\hline Knowledge of tsetse fly & $245(88.5 \%)$ & $320(91.2 \%)$ & $376(88.1 \%)$ & $406(99.5 \%)$ \\
Experience of tsetse bite & $205(83.3 \%)$ & $270(84.6 \%)$ & $331(88 \%)$ & $404(99.5 \%)$ \\
Knowledge of danger of tsetse bite & $212(77.7 \%)$ & $225(64.9 \%)$ & $207(50.7 \%)$ & $377(93.3 \%)$ \\
Danger associated with tsetse bite: & $139(65.6 \%)$ & $195(86.7 \%)$ & $180(87 \%)$ & $341(90.9 \%)$ \\
Disease & $54(25.5 \%)$ & $26(11.6 \%)$ & $23(11 \%)$ & $27(7.2 \%)$ \\
Pain/injury & $2(1 \%)$ & $1(0.4 \%)$ & $2(1 \%)$ & $2(0.5 \%)$ \\
Death & $17(8 \%)$ & $3(1.3 \%)$ & $2(1 \%)$ & $5(1.4 \%)$ \\
Others & & & & \\
\hline
\end{tabular}

Of 1490 respondents, $90.4 \%$ knew and could identify tsetse flies. Of these, $89.8 \%$ have experienced a bite by a tsetse fly and knew its bite is harmful (Table 3). The majority (83.3-99.5\%) of the respondents in all four areas have had experienced a tsetse bite. However, only about half $(50.7 \%)$ of respondents in Meatu district was knowledgeable of the dangers of the tsetse bite. Most respondents claimed to have been bitten by tsetse when visiting tsetse-infested areas such as tsetse flies. The dry season was cited as the time with the highest tsetse activity (62.2\%). During this season a person can receive as many as 200 tsetse bites per week particularly for people, such as park rangers, herdsmen, drivers and tour guides, whose daily activities involve working extended hours in tsetse infested areas (Figure 1). 


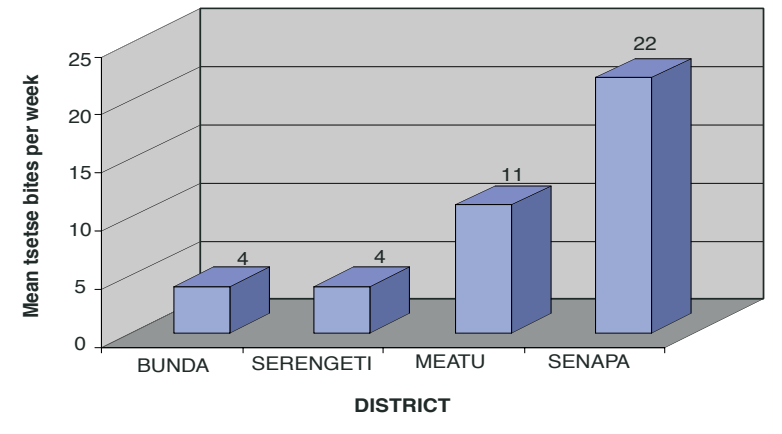

Figure 1: Mean number of tsetse bites per person per week

A significant proportion of respondents practiced at least one risk activity including frequent visiting and working in tsetse infested areas (72.7\%), visiting and/ or handling game animals $(21 \%)$ and grazing livestock in tsetse infested areas (48.9\%). It was also a common practice for people living in areas around SENAPA to take their dogs with them when visiting tsetseinfested areas ( $24.8 \%$ of all responses). In SENAPA, $90 \%$ of the respondents said that tsetse-infested bushes and forests were their working and/or living environment.

Over $97 \%$ of the respondents complained that there were neither tsetse nor sleeping sickness control measures been implemented in the three districts. However, there were major efforts to control tsetse and sleeping sickness within SENAPA (70.3\% of all responses). Control measures included installation of insecticide impregnated targets in tourist posts, campsites, roadsides, lodges and resident areas. Others were bush clearing around main roads, lodges and residential areas as well as spraying of vehicles with insecticides and use of insect repellents.

\section{Discussion}

Findings of this study show that communities living in and around SENAPA have adequate knowledge of sleeping sickness, its cause, transmission, risk factors, signs and symptoms as well as its prevention methods. In SENAPA knowledge was particularly higher compared to communities living outside the park. This can be attributed to the fact that the most recent outbreaks of sleeping sickness occurred within SENAPA and that the outbreak was followed by awareness campaigns. Another possible factor is the higher literacy level of SENAPA respondents, 45.3\% of whom had attained secondary education as compared to Bunda (10.6\%), Serengeti $(17.5 \%)$ and Meatu (2.4\%). Sleeping sickness was reported to be present in all surveyed villages and sites. The highest percentage of respondents reporting presence of sleeping sickness was found in SENAPA, a relatively short distance from adjacent villages where communities were also interviewed.

Northwestern parts of Tanzania including the Serengeti ecosystem have a long history of being endemic for sleeping sickness. Previous studies have demonstrated presence of human infective T. brucei spp circulating in game and domestic animals in the area (Moloo et al., 1971; Kaare et al., 2002). Recently, nine cases of sleeping sickness (T. brucei gambiense) involving tourists have been reported in the Tarangire and Serengeti National Parks (Jelinek et al., 2002). Very few cases in the local community were reported from health facilities (Kaare et al., 2002). The explanation for this could be that though sporadic cases may exist, there is no satisfactory surveillance and reporting from the local communities, the situation being complicated by lack of diagnostic and healthcare services. Furthermore, there is the possibility of sleeping sickness cases being easily mistaken for other febrile diseases like malaria (Malele et al., 2006) which are also prevalent in the area. This accompanied by low incidence and the sporadic nature of the disease makes it difficult to identify cases of sleeping sickness.

The mean number of tsetse bites per person per week represents the degree of tsetse-human contact or tsetse challenge. The recorded mean tsetse bites per person per week show a great variation between the three districts and SENAPA with the highest recorded in SENAPA. The figures may be an underestimation of the real life situation as certain species of tsetse e.g. G. swynnertoni which was identified as the most abundant species in a parallel entomological survey (data not shown) are known to draw blood meal from their hosts, undetected (Moloo et al., 1971). Higher number of tsetse bites per person per week represents the tsetse nuisance and risk for transmission of sleeping sickness for tourists and local staff. By itself, it justifies initiation and scaling up of tsetse and sleeping sickness control measures. Despite the knowledge about sleeping sickness and the right place where to seek health care, diagnostic as well as healthcare services are not available to the surveyed communities, which is a hindrance to prevention and control efforts. Similar findings have been recently reported in western Tanzania (Malele et al., 2006).

Overall, results of this study have shown that there is adequate knowledge and positive attitudes and practices of the communities living in and around 
SENAPA about tsetse and sleeping sickness. This means that communities can understand and support community-based tsetse and sleeping sickness control programmes to ensure success. Control measures should therefore be scaled up in SENAPA, and initiated in adjacent communities.

\section{Acknowledgements}

We thank the District Commissioners, District Medical Officers and District Veterinary Officers for Bunda, Serengeti and Meatu for facilitating this study. We also extend our sincere thanks to the management of SENAPA for the cooperation and support rendered to our research team. Our sincere gratitude also goes to the village leaders and the individual study participants whose understanding and cooperation made the accomplishment of this study possible. This work received financial support from the Tanzanian National Institute for Medical Research.

\section{References}

Davey, J.B. (1924) The outbreak of human trypanosomosis (Trypanosoma rhodesiense infection) in Mwanza district, Tanganyika Territory. Transactions of the Royal Society of Tropical. Medicine and Hygiene 17, 474-482.

Hide, G (1999) History of sleeping sickness in East Africa. Clinical Microbiology Reviews 12, 112125.

Jelinek, T., Bisoffi, Z., Bonazzi, L., van Thiel, P., Bronner, U., de Frey, A., Gundersen, S.G., McWhinney, P. \& Ripamont, D (2002) Cluster of African Trypanosomiasis in travelers to Tanzanian National Parks. Emerging Infectious Diseases 8, 634-635.

Kaare, M.T., Picozzi, K., Welburn, S.C., Mtambo, M.M., Mellau, L.S.B., Cleaveland, S. \& Mlengeya, T.D.K (2002) Sleeping sickness in Serengeti Ecological Zone: the role of wild and domestic animals as reservoir hosts for the disease. Proceedings of the Third Annual Scientific Conference of the Tanzania Wildlife Research Institute, Arusha, December 3-5, 2002. pp 204-217.
Malele, I,.I, Kibona, S.N., Matemba, L.E., Sahani, K., Swilla, J. Mwalimu C.D., Mayala, B.K., Kimaro, E., Msumary, C. \& Kalinga, R.B (2006) Human African trypanosomiasis and challenges to its control in Urambo, Kasulu and Kibondo districts, western Tanzania. Tanzania Health Research Bulletin 8, 80-85

Mboera, L.E.G., Rumisha, S.F., Senkoro, K.P., Mayala, B.K., Shayo, E.H. \& Kisinza, W. N (2005) Research on knowledge systems: Determination of Strategies and Approaches for a Successful Improvement of Gaps for Health Knowledge in Tanzania. Technical Report, August 2005. National Institute for Medical Research, Dar-es-Salaam, Tanzania.

Mlengeya, T. D. K., Muangirwa, C., Mlengeya, M. M., Kimaro, E., Msangi, S. \& Sikay, M (2002) Control of Sleeping Sickness in the Northern Parks of Tanzania. Proceedings of the Third Annual Scientific Conference of the Tanzania Wildlife Research Institute, Arusha, December 35, 2002. pp 274-282.

Moloo, S.K., Steiger, R.F., Brun, R. \& Boreham, P.F.L. (1971) Sleeping sickness survey in the Musoma District, Tanzania. Acta Tropica 28, 189-205.

Onyango, R. J. \& Woo, P.T.K (1971) Sleeping sickness survey in Musoma district, Tanzania. Acta Tropica 28, 181-188.

Swynnerton, C.F.M. (1923) The entomological aspect of an outbreak of sleeping sickness near Mwanza, Tanganyika Territory. Bulletin of Entomological Research 13, 317-370.

Swynnerton, C.F.M. (1925) The evidence as regards the game in the outbreak of human trypanosomiasis near Mwanza. Transactions of the Royal Society of Tropical Medicine and Hygiene 19, 70-80.

WHO (1998) Control and Surveillance of African Trypanosomiasis. Report of WHO Expert Committee. WHO technical Report Series No. 881. WHO, Geneva.

WHO (2002) African Human Trypanosomiasis. www.who.int/tdr/diseases/ default.html 